\title{
Geração de Trabalho e Renda em Comunidades na Amazônia: um olhar a partir das potencialidades e desafios da tecnologia social no Pará
}

Job and Income Generation in Amazon Communities: looking from the potentials and challenges of social technology in Pará

\author{
Emelyn Larissa Lima da Silva ${ }^{1}$ \\ Diana Cruz Rodrigues ${ }^{2}$ \\ Mário César Carvalho ${ }^{3}$
}

\begin{abstract}
Resumo:
O artigo discute as potencialidades e desafios da geração de trabalho e renda a partir da tecnologia social na Amazônia, especificamente no estado do Pará. Realizamos a pesquisa em duas fases: a primeira consistiu no levantamento de tecnologias sociais implementadas no Pará, com a temática de renda, na base de dados da Fundação Banco do Brasil. Esse levantamento forneceu uma amostra de 21 experiências de tecnologias sociais para construção de um panorama inicial e seleção de uma tecnologia social, a qual foi analisada na segunda fase da pesquisa por meio de um estudo de caso. A abordagem teórica-conceitual se posiciona no campo da gestão social ao buscar o imbricamento entre economia solidária e tecnologia social, enquanto uma alternativa para a geração de trabalho, renda e inclusão socioprodutiva. A maioria das tecnologias sociais identificadas teve como proponentes organizações da sociedade civil que atuavam em atividades de extrativismo e agricultura familiar. $\mathrm{O}$ caso analisado expressa potencialidades da tecnologia social e da economia solidária para geração de trabalho e renda na região a partir de uma prática extrativista que sofreu forte desregulamentação na década 1990, porém também retrata desafios que requerem enfrentamento. As principais potencialidades foram: a valorização dos recursos da floresta, a ampliação das oportunidades de geração de renda e a inclusão socioprodutiva, principalmente das mulheres. Os principais desafios foram: o tensionamento dos princípios da economia solidária pela lógica de mercado no processo de comercialização, dinâmicas de desigualdades (principalmente de gênero) e ausência de políticas públicas intersetoriais e de longo prazo.
\end{abstract}

Palavras-Chave: Amazônia; Geração de Trabalho e Renda; Tecnologia Social; Economia Solidária; Gestão Social.

\section{Abstract:}

The paper aims to discuss the potentials and challenges of work and income generating from social technology in the Amazon, specifically in Pará. For this purpose, we carried out the research in two phases, the first consisted of a survey

\footnotetext{
${ }^{1}$ E-mail: emellima97@gmail.com

2 Programa de Pós-Graduação em Administração - PPAD. E-mail: diana_rodrigues@yahoo.com

3 E-mail: carvalhomario@yahoo.com.br
} 
of social technologies implemented in Pará, with the theme of income, in the database of Fundação Banco do Brasil. This survey provided a sample of experiences for the construction of an initial panorama and selection of a social technology for a case study, in the second phase of the research. The theoreticalconceptual approach is positioned at the intersection of social technology and solidarity economy, as an alternative for the generation of work, income, and socioproductive inclusion. The survey identified 21 social technologies with the theme of income implemented in 27 municipalities in Pará. Most of them had civil society organizations as proponents, based in the state itself and focused on extractivism and family farming activities. The case expresses the potential of social technology and solidarity economy to generate work and income in the region from an extractive practice that suffered strong deregulation in the 1990s, but it also portrays challenges that require confrontation. The main potentialities were the valorization of the forest resources, the expansion of income generation opportunities and the socio-productive inclusion, mainly of women. The main challenges were the tensioning of the principles of solidary economy by the market logic in the commercialization process, inequalities dynamics (mainly gender) and the absence of intersectoral and long-term public policies.

Keywords: Amazon; Job and Income Generation; Social Technology; Solidarity Economy; Social Management.

\section{Introdução}

A pesquisa objetiva analisar experiências de geração de trabalho e renda na Amazônia a partir de uma amostra de tecnologias sociais implementadas no estado do Pará. Dentre as experiências catalogadas, aprofundamos a investigação em um caso específico, a fim de melhor entender suas estratégias de implementação, potencialidades e desafios. Compreendemos que a tecnologia social associada aos princípios da economia solidária pode ser uma alternativa para geração de trabalho e renda na Amazônia, que valorize a cultura, o meio ambiente e os conhecimentos dos atores locais. Assim, tal alternativa tem como ponto de partida uma construção de desenvolvimento endógena, contrapondo-se à lógica historicamente institucionalizada na região de grandes projetos ditos de desenvolvimento, baseados na importação de pacotes tecnológicos e organizacionais externos, com foco na geração e exportação de insumos de interesse internacional, como exemplo a expansão do agronegócio de soja na região (BARROS et al., 2020).

Durante o século $X X$, houve considerável desenvolvimento tecnológico e crescimento econômico, principalmente situados em grandes metrópoles mundiais, porém também se observou a persistência de problemas socioeconômicos, como a pobreza, a exclusão social e desigualdades, bem como a aceleração da degradação ambiental. Esse cenário levou à emergência da concepção de desenvolvimento que tem como base a sustentabilidade em suas múltiplas dimensões: econômica, social, ambiental, política e cultural (SACHS, 2008). A partir de então, diversas concepções de desenvolvimento têm sido formuladas, como o desenvolvimento sustentável (SACHS, 2008), o desenvolvimento local (ESPADA; VASCONCELLOS SOBRINHO, 2015), o desenvolvimento territorial (DALLABRIDA, 2010) até emergir um conjunto de discussões críticas sobre desenvolvimento na perspectiva do pós-desenvolvimento (RADOMSKY, 2011). Nesta pesquisa, não iremos nos aprofundar em discussões teóricas e conceituais sobre o desenvolvimento, porém é preciso pontuar que buscamos compreender processos de geração de trabalho e renda no contexto 
de sociedades amazônicas, tendo em vista dois princípios básicos discutidos nesta literatura: a natureza multidimensional da transformação social (portanto, descentrada da dimensão econômica) e a sua construção endógena.

Uma alternativa para pensarmos desenvolvimento tecnológico que atenda aos princípios acima estabelecidos é a tecnologia social (TS). A TS é conceituada como produtos, metodologias ou técnicas desenvolvidas na interação com a comunidade, que visem a criar transformações sociais (RTS, 2005; FBB, 2020). É uma concepção de tecnologia que busca aliar o desenvolvimento de conhecimentos científicos com os saberes populares ou tradicionais de comunidades. Portanto, é uma concepção tecnológica que tem como centralidade a sociedade na qual será desenvolvida e aplicada, considerando suas necessidades, seus recursos, princípios e valores.

Na década de 2000, a região Amazônia havia sido selecionada como uma das áreas prioritárias para investimento em TS pela Rede de Tecnologias Sociais (RTS) devido à precariedade de condições de vida de parte de sua população, além das pressões ambientais na região. Apesar da própria RTS ter investido relativamente pouco na região amazônica, apenas 1\% no período de 2005 a 2011 (THEIS; STRELON; LASTA, 2017), diversas iniciativas de TS foram e têm sido desenvolvidas na Amazônia. Neste artigo, buscamos evidenciar algumas dessas experiências e discutir potencialidades e desafios de desenvolver soluções tecnológicas para inclusão socioprodutiva a partir dos recursos naturais, dos conhecimentos e dos valores dos grupos sociais na região.

Ao focar as TS aplicadas à geração de trabalho e renda, nos aproximamos dos princípios da Economia Solidária, pela busca de conciliação entre a dimensão econômica e social (FRANÇA FILHO, RIGO, SOUZA, 2020). Entendemos que a concepção de TS se adequa e tende a fortalecer a perspectiva da economia solidária ao promover o desenvolvimento e a reaplicação de tecnologias em comunidades, inclusive aquelas de baixa renda e excluídas de oportunidades de empregos formais. Como discutiremos, o desenvolvimento tecnológico, a partir de princípios democráticos defendidos pela TS, proporciona uma base tecnológicaprodutiva compatível com os princípios de finalidade social e autogestão da economia solidária (FRANÇA FILHO, RIGO, SOUZA, 2020) e do campo mais amplo de gestão social (CANÇADO, 2007).

Assim, para pesquisar a temática de TS na confluência com a economia solidária, nossa pesquisa envolveu duas etapas metodológicas. Na primeira, realizamos um levantamento na base de dados da Fundação Banco do Brasil (FBB) para busca das TS implementadas no Pará, em especial, aquelas classificadas na temática de geração de renda. Esse levantamento permitiu um panorama geral dessas experiências de TS no estado do Pará, identificando características e atributos. Na segunda etapa, selecionamos um dos casos dentre as TS implementadas em comunidades da Amazônia paraense. Esse aprofundamento objetivou compreender as estratégias de implementação adotadas na região, bem como as potencialidades de geração de trabalho e renda e os desafios enfrentados.

Esse artigo está organizado em cinco (5) seções, tendo esta introdução como a primeira. A segunda seção corresponde ao referencial teórico-conceitual, no qual os quadros analíticos sobre TS e Economia Solidária são construídos. Na terceira seção, o desenho metodológico da pesquisa é apresentado. Na quarta seção, os resultados são apresentados e discutidos. E, por fim, a quinta seção corresponde às considerações finais sobre a pesquisa.

\section{Construção do Quadro Analítico-Conceitual: Tecnologia Social e Economia Solidária}


Ao buscar analisar experiências de tecnologia social (TS) de geração de trabalho e renda na Amazônia paraense, torna-se necessário estabelecer um quadro analítico-conceitual que auxilie no exame de atributos principais destas experiências e que direcione a discussão dos resultados. Entendemos que estas experiências de TS apresentam duas interfaces temáticas: uma relacionada à concepção sobre tecnologia; outra relacionada à concepção sobre a forma organizativa dos empreendimentos socioprodutivos que fazem uso das tecnologias sociais. Portanto, abordamos nesta seção duas temáticas que se interrelacionam no escopo da pesquisa: (1) a temática de TS, enquanto categoria chave da face tecnológica da pesquisa e (2) a temática de economia solidária (ES), enquanto categoria chave da face organizacional da pesquisa, com aporte sobre as características dos empreendimentos socioprodutivos.

\subsection{Tecnologia Social}

A concepção de TS consolidou-se a partir do ano de 2005 no Brasil, tendo à época como importante arena de discussão a Rede de Tecnologia Social (RTS). A RTS (2010) tem, em sua prerrogativa, a união de organizações governamentais e não-governamentais, com o objetivo de construir possibilidades de geração de mudanças sociais. Diversos tipos de iniciativas e projetos sociais podem fazer uso da concepção de TS na busca pelo aperfeiçoamento de suas atuações para a transformação social. Entendemos que o conceito de TS, consensuado na RTS e citado na introdução, realça dois princípios: o do desenvolvimento (ou reaplicação) tecnológico a ser realizado na interação com a comunidade e o da busca pela transformação social, como discutiremos neste tópico.

É necessário informar que o conceito de TS apresenta antecessores, sendo os principais o da tecnologia apropriada e da tecnologia intermediária. Essas propostas alternativas de desenvolvimento tecnológico estão entre aquelas denominadas por Thomas, Juarez e Picabea (2015) como sendo de primeira geração de tecnologias para inclusão social. A tecnologia apropriada havia sido concebida como "um conjunto de técnicas de produção que utiliza de maneira ótima os recursos disponíveis de certa sociedade, maximizando, assim, seu bem-estar" (DAGNINO; BRANDÃO; NOVAES, 2010, p. 07). E a tecnologia intermediária correspondia a "uma tecnologia que, em função de seu baixo custo de capital, pequena escala, simplicidade e respeito à dimensão ambiental, seria mais adequada para países pobres" (DAGNINO; BRANDÃO; NOVAES, 2010, p. 06). Por conseguinte, a proposição de TS percorre uma trajetória de concepção de desenvolvimento e de uso de tecnologias em contextos alternativos àqueles de aplicações industriais convencionais, tendo como objetivo a resolução de problemas sociais de grupos vulneráveis ou em situação de exclusão socioprodutiva.

Uma segunda geração de tecnologias para inclusão social é realçada por Thomas, Juarez e Picabea (2015). Esses autores apresentam algumas concepções tecnológicas mais recentes como as de TS, de inovação responsável, de inovação de base (grassroots) e de inovação social. Algumas dessas concepções permaneceram com um forte viés pró-industrial (como a inovação responsável), outras mais circunscritas a artefatos de baixo conteúdo tecnológico para microempreendedores, como a inovação de base (VASEN, 2016). Enquanto a concepção de inovação social, no nosso entender, é a que apresenta maior polissemia e de fluidez conceitual em diferentes áreas do conhecimento por está mais preocupada com os processos e práticas sociais (VASEN, 2016; VASCONCELLOS SOBRINHO et al., 2020).

Nesse contexto, a TS é uma construção conceitual que carrega motivações relacionadas a conceitos antecessores e dialoga com enfoques mais novos de tecnologias para inclusão social. A seguir iremos ressaltar suas concepções, características ou propriedades específicas. O termo de TS também tem suscitado certa polissemia. Neste artigo, partiremos do marco analítico conceitual seminal de TS proposto por Dagnino, Brandão e Novaes (2004) e Novaes e Dias (2009); além de buscar suporte em outras referências teóricas-conceituais e técnicas do campo. 
Segundo Schoab, Freitas e Lara (2014), o termo tecnologia é entendido como a manifestação aplicada do conhecimento, que pode se dar por meio de processos, produtos, metodologias ou técnicas, que são utilizadas de acordo com uma intervenção coletiva, seja por meio do Estado ou pelas organizações da sociedade. A junção dos termos tecnologia e social é o que fomentou a proposta da TS, de modo a oferecer alternativas tecnológicas para a melhoria das condições de vida em sociedade. Como exemplo, a Fundação Banco do Brasil (2020) remete o termo "Social" para as tecnologias que buscam soluções para os problemas sociais, como: a ausência de educação, habitação, renda, alimentação, entre outros. Assim, a primeira aproximação ao conceito de TS está na finalidade da tecnologia estar voltada a resolver problemas sociais ou prover transformações sociais.

Para além desse direcionamento, a forma como tal tecnologia é desenvolvida é relevante. No caso das TS, elas se fundamentam pelo desenvolvimento e uso de tecnologias que sejam elaboradas por meio dos (ou em interação com) saberes populares, técnicos ou tradicionais de seus usuários. Isso porque a TS está baseada no conceito de construção sociotécnica, pelo qual os artefatos têm suas características constituídas por negociações entre os "grupos sociais relevantes" no contexto de seu processo de desenvolvimento tecnológico. Estes grupos possuem preferências e interesses diferentes, o que implica no emprego de critérios econômicos, políticos, sociais e técnicos, de natureza distintas, durante o desenvolvimento dos artefatos (BIJKER, 1995). Este entendimento, portanto, torna importante observar quais são os grupos sociais que conseguem participar e influenciar os critérios e valores a constituírem o processo de desenvolvimento tecnológico.

A ideia de interação com a comunidade para o Instituto de Tecnologia Social (ITS) (2018, p. 19) coincide com a concepção que "as tecnologias sociais se fazem mediante a participação das próprias pessoas às quais se destinam. Seu público usuário precisa ser sujeito ativo também da idealização e execução". Isto posto, o ITS orienta que os usuários da TS precisam exercer dois papéis quanto à tecnologia: (1) o de participar diretamente na construção, elaboração e/ou reaplicação da tecnologia; e (2) o de participar na tomada de decisão sobre o uso e aplicação dessas tecnologias, dentro das comunidades, ou dos empreendimentos. Esse modelo de desenvolvimento tecnológico está centrado, dessa forma, nos grupos sociais, enquanto coprodutores da tecnologia.

A relevância da participação e coprodução dos usuários no desenvolvimento tecnológico também apresenta implicações nas dinâmicas de disseminação tecnológica. Na literatura de TS, a partir do caráter de adequação sociotécnica, é defendida a noção de "reaplicação" em contraposição à replicação. A reaplicação de uma TS é um processo de desenvolvimento tecnológico específico que, embora tenha como ponto de partida a ideia de uma TS anteriormente concebida, combina-se com aspectos próprios do contexto sociotécnico em que será (re)aplicada, como as características ambientais e as relações sociais estabelecidas entre os atores locais participantes (DAGNINO; BRANDÃO; NOVAES, 2004). Portanto, os aspectos concebidos na TS original precisam ser aprendidos e combinados com atributos próprios do contexto sociotécnico e atores do local em que será reaplicada, de modo que a reaplicação depende de um processo de avaliação e apropriação local da solução originalmente proposta para outro contexto.

Entendemos que este princípio de participação dos usuários no processo de desenvolvimento tecnológico (ou reaplicação) associa-se ao compromisso de promover a emancipação destes, fundamental para alcance da transformação social. De acordo com a RTS (2010, p. 14), a base para a transformação da realidade dos indivíduos e grupos sociais está inicialmente na compreensão desta realidade, percebida como um posicionamento sociopolítico, que busca entender as diferentes causas dos problemas enfrentados, inclusive aquelas de natureza estrutural. Perante esta ênfase à transformação social, Thomas (2009) realça que a TS é uma alternativa ao formato de desenvolvimento tecnológico convencional da lógica capitalista, embora possamos identificar concepções de TS de teor tanto reformista (FBB, 2020), quanto de ruptura (DAGNINO, 2014) com esta lógica capitalista. Contudo, ambas as linhas de concepções de TS se voltam a produtores e consumidores de baixo poder econômico e direcionam os processos tecnológicos de modo a 
incentivar a capacidade de apropriação tecnológica do produtor, bem como de seus usuários, para que venham a adquirir potencialidade econômica e social (ARAÚJO; CÂNDIDO, 2015).

Assim, associada à transformação social está a geração de conhecimento e a aprendizagem sobre os problemas sociais vivenciados e suas possíveis soluções tecnológicas. Segundo o ITS (2007), isso se relaciona a um processo de pesquisa, que pode mobilizar conhecimentos populares, científicos e tecnológicos. Segundo a Fundação Banco do Brasil (FBB, 2004), a participação e a aprendizagem são processos interrelacionados, pelos quais a transformação social é construída a partir da compreensão da realidade, de maneira sistêmica, respeitando a capacidade de gerar conhecimento e de aprender da comunidade.

A interação da comunidade deve partir da participação coletiva e democrática nesta, seja para o desenvolvimento ou reaplicação da TS, seja para a decisão dos usos presentes e futuros desta. A interação e participação da comunidade permite construir o conhecimento e a aprendizagem, a fim de solucionar um problema em foco. Bem como, o aprendizado desenvolvido proporciona o empoderamento nesta comunidade para utilizar tal lógica de construção de TS para resolver outros problemas, o que leva a considerar a TS um instrumento pedagógico, pelo qual a comunidade aprende no construir das soluções.

Em síntese, no quadro 1 apresentamos as propriedades de TS que serviram de base analítico-conceitual, para esta pesquisa.

Quadro 1 - Categoria de Tecnologia Social

\begin{tabular}{|c|l|}
\hline \multicolumn{2}{|c|}{ Categoria } \\
\hline Tecnologia Social & $\begin{array}{l}\text { São produtos, técnicas ou metodologias, reaplicáveis, desenvolvidos em interação } \\
\text { com a comunidade e que representem efetivas soluções de transformação social } \\
\text { (RTS, 2005; ITS, 2018; FBB, 2021). }\end{array}$ \\
\hline \multicolumn{2}{|c|}{ Propriedades de Análise } \\
\hline $\begin{array}{c}\text { Participação local } \\
\text { (desenvolvimento em } \\
\text { interação com a } \\
\text { comunidade) }\end{array}$ & $\begin{array}{l}\text { As tecnologias sociais são desenvolvidas mediante a participação direta e } \\
\text { democrática das pessoas às quais se destinam, de modo que seu usuário precisa } \\
\text { ser sujeito ativo da idealização, execução e apropriar-se de processos decisórios } \\
\text { relacionados à tecnologia. }\end{array}$ \\
\hline $\begin{array}{c}\text { Transformação } \\
\text { Social }\end{array}$ & $\begin{array}{l}\text { O objetivo do desenvolvimento e aplicação da TS é a transformação social, a qual } \\
\text { implica em: (1) compreender a realidade de maneira sistêmica, por meio de (2) } \\
\text { processos de geração de conhecimento e aprendizagem baseado nas pessoas e } \\
\text { ambiente do contexto local de aplicação. }\end{array}$ \\
\hline Reaplicação & $\begin{array}{l}\text { O processo de aprendizagem, avaliação e apropriação de uma solução tecnológica } \\
\text { proposta em outro contexto por parte das pessoas de um novo contexto local a fim } \\
\text { de realizar a adequação sociotécnica da solução para seus próprios recursos, } \\
\text { valores e ambiente. }\end{array}$ \\
\hline
\end{tabular}

Fonte: Elaborado pelos autores a partir das referências discutidas nesta seção.

\subsection{Economia Solidária}

Nesta pesquisa, analisaremos as TS que tratam, especificamente, de geração de trabalho e renda. Deste modo, compreendemos necessário estabelecer bases analíticas-conceituais relacionadas aos processos de inclusão socioprodutiva. Vimos que a TS implica em uma proposta alternativa de desenvolvimento tecnológico, a qual deve se relacionar a uma concepção necessariamente alternativa dos processos de produção e de relações econômicas. Nesse contexto, a economia solidária (ES) se torna a segunda face analítica da pesquisa, dando suporte aos princípios e conceitos para inclusão socioprodutiva, por meio de empreendimentos para geração de trabalho e renda. 
No âmbito de políticas e ações públicas para geração de trabalho e renda no Brasil, o conceito de ES geralmente convive com outros repertórios analíticos-conceituais. França Filho (2002) e França Filho, Rigo e Souza (2020) discutem suas fronteiras conceituais com repertórios como o do terceiro setor (de origem anglo-saxônica, de inspiração na econômica neoclássica com enquadramento suplementar funcional aos demais setores), o da economia social (de origem europeia, inspirada em movimentos de ajuda mútua, com base em princípios associativistas), o da economia popular (de origem da América Latina, de base comunitária e de saberes locais, mas muitas vezes associada - ou sem a devida diferenciação conceitual com - a informalidade e condições precárias de funcionamento) e, mais recentemente, o dos negócios sociais (de origem indiana com forte influência anglo-saxônica, mais alinhada à lógica de mercado). A escolha pela ES (ou da economia popular e solidária) nesta pesquisa se baseou pela proposta de maior potencial de reconciliação entre economia e social, por seu compromisso não somente com a finalidade social, mas também com uma forma alternativa de ação e gestão organizacional.

Os antecedentes da ES são os mesmos relacionados à inspiração da economia social, baseados nas experiências associativistas da primeira metade do século XIX na Europa, como as denominadas as sociedades de socorro mútuo, em contraposição às condições de pauperização dos trabalhadores na expansão capitalista. Essas iniciativas conceberam o embrião inicial da noção de proteção social, posteriormente adotada pela função redistributiva do Estado, como, por exemplo, no sistema previdenciário estatal (FRANÇA FILHO, 2002; NARDI et al., 2005). Contudo, no caso das organizações da economia social, embora mantenham sua finalidade social, tenderam em seu processo de institucionalização no século $\mathrm{XX}$ a ter sua forma de gestão apropriada pela lógica de estatal ou empresarial (FRANÇA FILHO, 2002; FRANÇA FILHO; RIGO; SOUZA, 2020).

O termo "economia solidária" emergiu no contexto de crise do Estado de Bem-Estar, em um novo momento de reconfiguração da regulamentação econômica e das relações de trabalho, pela predominância de uma concepção neoliberal e pressão no Estado para adoção de mecanismos de maior desregulamentação. Assim, a noção de ES surgiu por iniciativas locais com um novo e alternativo caráter quanto ao seu funcionamento e a sua finalidade, ou seja, a geração de atividades econômicas com finalidades socais, opondo-se à autonomização do mercado e objetificação de relações sociais (FRANÇA FILHO, 2003). Deste modo, é um movimento que amparado na noção de uma economia com base na solidariedade busca oferecer soluções aos problemas do desemprego, da precarização do trabalho e da pobreza e exclusão socioprodutiva (NARDI et al., 2005).

Do ponto de vista conceitual, a construção da proposta da ES se opõe à leitura restritiva neoclássica sobre o funcionamento da economia e do comportamento econômico preponderante sobre o social. A ES retoma a necessidade da integração entre as dimensões econômica, social e política, assumindo o enraizamento ou a dissolução da economia no social (FRANÇA FILHO; RIGO; SOUZA, 2020; POLANYI, 2000). O termo foi forjado inicialmente na literatura francesa para explicar iniciativas associativas que buscavam resolver problemas locais, reunindo duas noções: iniciativas econômicas e solidariedade (FRANÇA FILHO, 2003).

No Brasil, um marco de referência inicial foram os trabalhos de Paul Singer desde o final dos anos 1990 (SINGER, 2008; FRANÇA FILHO; RIGO; SOUZA, 2020). Para Lima et al. (2011), o termo de ES emergiu no país ao buscar dar respostas ao aumento do desemprego e exclusão social em meio ao rápido processo de abertura da economia brasileira, seguindo ditames neoliberais. Este processo levou ao fechamento de várias fábricas e negócios locais, ampliando os níveis de informalidade e precarização do trabalho.

A resolução de problemas relacionados à geração de trabalho e renda pela via da ES é buscada pela reconciliação do econômico e do social. Para isso, a ES se estabelece como um espaço na interseção do Estado, do mercado e do informal, visando a propor um novo modo de regulação (FRANÇA FILHO, 2003). Segundo França Filho (2003), a ES se baseia em dois fundamentos: (1) o da hibridação de lógicas econômicas em que articulam distintas fontes de recursos pela combinação de uma economia mercantil (lógica de mercado), não-mercantil (lógica estatal/pública) e não-monetária (lógica doméstica/voluntariado), 
neste sentido as experiências de ES lidam com uma pluralidade de princípios econômicos; (2) o da construção conjunta da oferta e da demanda, de modo que os serviços ou produtos são concebidos em função das necessidades sociais reais exprimidas localmente, por meio da interação entre os diferentes participantes da iniciativa (FRANÇA FILHO, 2003).

Do ponto de vista analítico, adotaremos nesta pesquisa duas propriedades propostas por França Filho, Rigo e Souza (2020) para caracterização de empreendimentos de ES relacionadas à finalidade da gestão e ao modo de operar a gestão. Para os autores, a propriedade da finalidade da gestão corresponde aos princípios, diretrizes e normas que orientam a iniciativa socioprodutiva em análise, a qual deve responder ao predomínio da utilidade social sobre a viabilidade financeira. Assim, a ocorrência da atividade produtiva, e sua dinâmica socioeconômica, deve responder por demandas e valores para além dos econômicos, como os de afirmação identitária, de valorização de vínculos sociais, de conservação ambiental e de saúde coletiva e/ou de fortalecimento de lutas políticas (FRANÇA FILHO, RIGO E SOUZA, 2020). Por conseguinte, os interesses na produção, comercialização e renda são conciliados e condicionados ao estabelecimento e manutenção de relações de reciprocidade local, da melhoria da qualidade de vida de todos os participantes e da geração de conhecimentos, capacitação e autonomia.

Quanto à propriedade do modo de operar da gestão, França Filho, Rigo e Souza (2020) definem que esta corresponde ao modo como ocorrem o processo de tomada de decisão e a condução da gestão, ou seja, os princípios, diretrizes e normas da dinâmica da gestão organizacional da iniciativa em análise. Sendo que, no caso da ES, deve prevalecer os princípios da governança democrática de forma a conduzir práticas de gestão orientadas a partir de dinâmicas coletivas e participativas, de modo a viabilizar o caráter de apropriação social sobre a gestão. Esta propriedade visa a colocar a dimensão social em frente à econômica, contrapondo-se a uma visão tecnocrática da gestão. Desta forma, entendemos que o modo de operar a gestão pela ES corresponde aos princípios da Gestão Social, enquanto a busca de uma gestão democrática e participativa, cuja racionalidade fundamenta-se sobre valores de justiça social e não apenas na conformidade do mercado (TENÓRIO, 2008).

Nesta perspectiva, tanto a ES quanto a Gestão Social tem como um de seus pilares o processo de autogestão, enquanto a contraposição à heterogestão, pela qual se separa o grupo dos dirigentes (gestores) e o grupo dos dirigidos (demais trabalhadores), que ficam destituídos do poder de tomada de decisão na organização, incluindo quanto a determinação do esforço que será agregado em cada atividade (CANÇADO, 2004). Segundo Cançado (2004), a autogestão, enquanto um modo de organização do trabalho, se caracteriza: (1) pela ausência de separação entre sua concepção e sua execução, (2) pela coletividade dos meios de produção e (3) pela constituição desta como um processo de educação em constante construção na organização. França Filho (2003) retrata a forma de gestão da ES como uma organização de pessoas iguais, baseada em relações de poder paritárias, em que os processos de tomada de decisão são horizontais, dialogados e constituídos por consensos.

Contudo, sendo a heterogestão o modelo hegemônico nas organizações de trabalho do sistema capitalista (hierarquias baseadas no controle vertical), seja nas organizações estatais, seja nas organizações de mercado, o exercício da autogestão se contrapõe às práticas institucionalizadas de gestão e requer um processo de aprendizagem e reflexividade constante de seus membros, de modo a descontruir as práticas institucionalizadas. Nesse sentido, França Filho, Rigo e Souza (2020) caracterizam o modo de operar a gestão de empreendimentos de ES como um processo de aprendizagem para uma cultura de governança democrática, baseado em práticas autogestionárias. Devido aos tensionamentos das lógicas de mercado e estatais sobre os empreendimentos de ES, os autores observam que tais empreendimentos podem apresentar diferentes graus de maturidade em termos dessas práticas. Há empreendimentos com práticas avançadas de decisão dialogada em que há transparência e participação dos membros nos processos de tomada de decisão, com adequada rotatividade nos papéis de gestão e liderança do coletivo. Porém, em estágios de menor maturidade, é comum encontrar empreendimentos que estimulam a participação dos 
membros em tomadas de decisão e buscam exercer transparência nos processos gestão, mas carecem de paridade no diálogo e de renovação das lideranças. (FRANÇA FILHO; RIGO; SOUZA, 2020).

Em síntese, no quadro 2 apresentamos as propriedades da categoria de ES que serviram de base analíticoconceitual para esta pesquisa.

Quadro 2 - Categoria de Economia Solidária

\begin{tabular}{|c|c|}
\hline \multicolumn{2}{|r|}{ Categoria } \\
\hline Economia Solidária & $\begin{array}{l}\text { Modo de regulação das relações socioeconômicas constituído em um espaço de } \\
\text { interseção do Estado, do mercado e do informal, resultando na pluralidade de } \\
\text { princípios econômicos mercantis, não-mercantis e domésticas, pelo qual é buscada a } \\
\text { reconciliação do econômico e do social. }\end{array}$ \\
\hline \multicolumn{2}{|r|}{ Propriedades de Análise } \\
\hline Finalidade social & $\begin{array}{l}\text { Os princípios, diretrizes e normas de utilidade social devem predominar sobre a } \\
\text { viabilidade financeira na orientação da iniciativa socioprodutiva, de modo que a } \\
\text { decisão e desenvolvimento da atividade produtiva responda a demandas e valores } \\
\text { para além daqueles eminentemente econômicos, estando conciliados e } \\
\text { condicionados ao estabelecimento e manutenção de relações de reciprocidade, } \\
\text { melhoria da qualidade de vida dos participantes e geração de conhecimentos e } \\
\text { autonomia. }\end{array}$ \\
\hline $\begin{array}{l}\text { Gestão orientada pela } \\
\text { governança } \\
\text { democrática }\end{array}$ & $\begin{array}{l}\text { O modo de operar da gestão organizacional da iniciativa deve se basear nos } \\
\text { princípios da governança democrática e em práticas de autogestionárias, } \\
\text { orientadas a partir de dinâmicas coletivas e participativas, de modo a viabilizar o } \\
\text { caráter de apropriação social sobre a gestão. }\end{array}$ \\
\hline
\end{tabular}

Fonte: Elaborado pelos autores a partir das referências discutidas nesta seção.

\section{Percurso metodológico}

A presente pesquisa teve uma orientação qualitativa e foi realizada em duas etapas: (1) a primeira etapa correspondeu a um levantamento exploratório de TS implementadas no estado do Pará com foco na geração de trabalho e renda para um panorama geral de características destas experiências; e (2) a segunda etapa foi um estudo de caso sobre uma TS selecionada de forma investigar as categorias de TS e ES a partir dos quadros analítico-conceituais.

O levantamento de TS implementadas foi realizado pelo banco de TS certificadas da Fundação Banco do Brasil (FBB) (plataforma Transforma!), utilizando tanto o filtro por Unidade Federativa (PA), quanto pelo tema principal da TS (renda). Esse levantamento foi feito em 2020, abrangendo TS certificadas de 2003 a 2019. São relativamente poucas as opções de bases de dados sobre implementação de TS no país e na região Amazônica, várias bases são organizacionais (como bases de TS de universidades públicas e de institutos de pesquisa, com períodos de cobertura e conceituações distintos), por isso a escolha da base de dados da FBB decorreu por esta permitir uma boa cobertura longitudinal, estar vinculada a chamadas para prêmio e certificação bienais regulares (indução para submissão à base e estabilidade conceitual) e de reunir TS de múltiplas organizações em âmbito nacional.

A partir do levantamento e exame exploratório do panorama geral da amostra das experiências de TS de geração de renda identificada, selecionamos uma TS para estudo de caso de forma a podermos aprofundar a análise a partir dos quadros analíticos-conceituais. A escolha da TS se deu em função desta ter sido premiada como TS vencedora nacional na chamada de 2007 da FBB, já tendo mais de 20 anos de 
reaplicações junto a diferentes grupos sociais da região (indígenas, seringueiros, quilombolas, ribeirinhos e assentados de reforma agrária).

Adotamos a perspectiva de estudo de caso de Yin (2001), enquanto a realização de uma pesquisa com um fenômeno contemporâneo, dentro de um contexto de vida real e cujo contexto territorial exerce influência sobre o fenômeno (caso) em estudo. O estudo de caso realizado é de caráter exploratório e descritivo sobre a implementação de TS em comunidades na Amazônia paraense, dado o tema de TS na Amazônia ainda requerer maiores aprofundamentos de pesquisa, tendo como objetivo compreender as estratégias de implementação da TS e levantar potencialidades e desafios quanto à geração de trabalho e renda no contexto regional.

Para coleta de dados da etapa de estudo de caso, foram utilizadas a pesquisa documental e uma entrevista semiestruturada os responsáveis da organização proponente da TS. A pesquisa documental abrangeu documentos, sites e reportagens relacionados à TS e às organizações envolvidas em sua implementação.

\section{Resultados e Discussões}

Nesta seção, inicialmente, analisaremos os dados referentes ao universo das TS implementadas no estado do Pará, com o tema principal de geração de renda. O objetivo é apresentar um panorama geral das experiências identificadas. Em seguida, discutiremos o estudo de caso sobre a TS selecionada, "Encauchados de Vegetais da Amazônia", quando buscaremos entender a trajetória de implementação desta TS ao longo do tempo e entre diferentes grupos sociais, a fim de evidenciar potencialidades e desafios.

\subsection{Tecnologias Sociais com o Tema de Geração de Renda na Amazônia Paraense}

Segundo levantamento na base de dados de tecnologias sociais certificadas pela Fundação Banco do Brasil (FBB), identificamos no total 77 TS implementadas em 68 municípios do estado do Pará, entre os anos de 2003 até 2019, contemplando diversos temas: alimentação, educação, energia, meio ambiente, recursos hídricos, renda e saúde. Dentre os temas principais das TS implementadas no Pará, o tema de renda é o segundo mais frequente na base de dados (27\% das TS), com 21 TS implementadas certificadas, ficando atrás somente do tema de Meio Ambiente (30\%). Entendemos que esse percentual evidencia que o tema de geração de renda e reconhecido como uma demanda e apresenta potencial de responsividade por meio do desenvolvimento de TS.

Gráfico 1: TS certificadas pela FBB como implementadas no estado do Pará, no período de 2003 a 2019 , por número total e por número do tema de renda. 


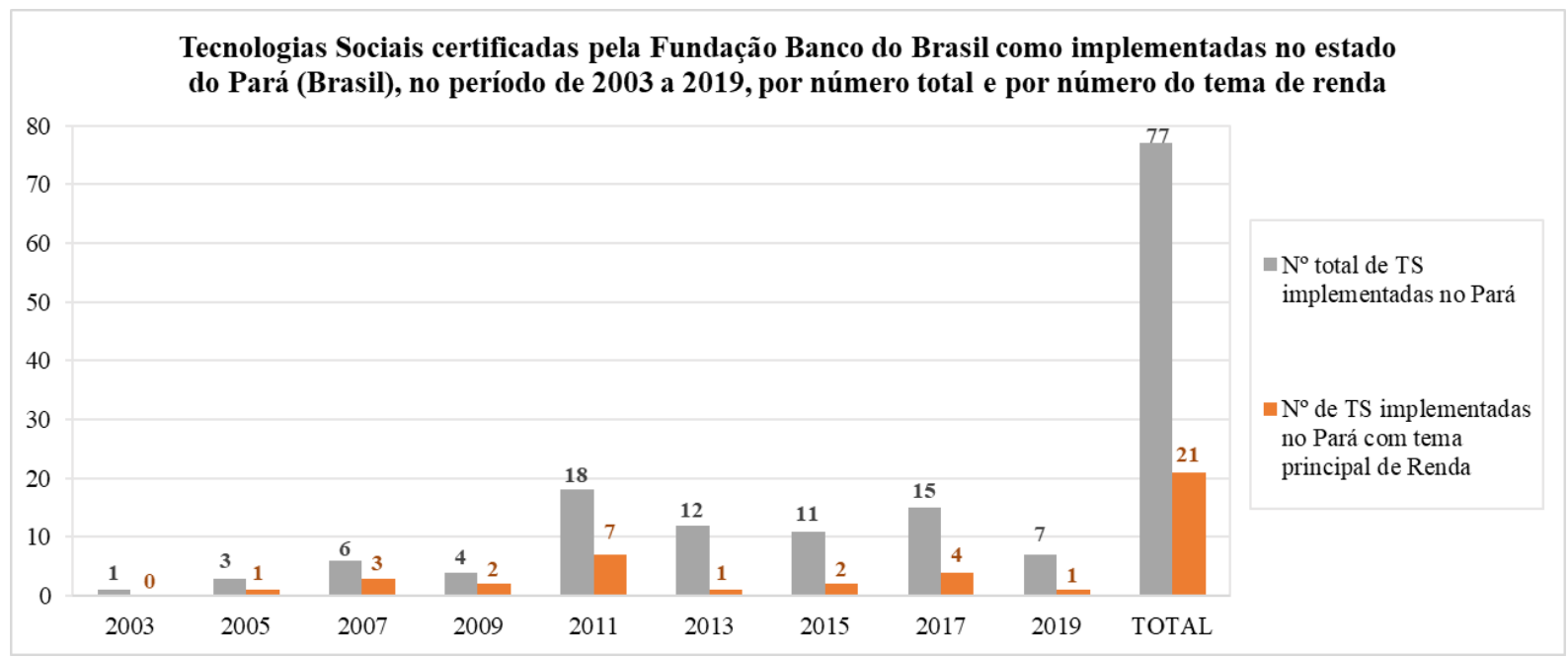

Fonte: Elaborado pelas autoras.

Conforme gráfico 1, observamos que TS relacionadas ao tema principal de renda foram certificadas desde a chamada de 2005 da FBB, permanecendo presentes em todas as chamadas bienais posteriores, com destaque para os anos de 2007 (50\% das TS certificadas tiveram como tema principal renda) e 2011 (chamada com maior número de TS certificadas no estado no tema). Contudo, dado o potencial para implementação de TS e para a demanda de geração de trabalho e renda por meios sustentáveis na região (e no estado do Pará), consideramos um nível de implementação aquém das necessidades regionais. Se, por um lado, esses números podem refletir uma limitação de alcance da base de dados, por outro lado, alerta sobre possíveis lacunas de indução e de políticas públicas de fomento à temática na região, lembrando como anteriormente citado o baixo nível de investimento da própria RTS na região.

As 21 TS implementadas no estado do Pará no tema principal de renda registraram execução em 27 municípios do total de 144 no estado, sendo o município de Belém (capital do estado) com 3 TS implementadas, Santarém e São Francisco do Pará com 2 TS e demais com uma TS somente. Embora encontremos 2 TS implementadas em até 5 municípios, a maioria das TS identificadas (14) foi registrada como implementada em somente um município. Isso suscita haver um potencial para reaplicação das TS identificadas em outros municípios do estado que apresentem demanda de geração de renda e contextos similares. Porém, também reforça a necessidade de criação de políticas públicas de fomento à TS, especificamente de ações que contemplem a indução à disseminação tecnológica via reaplicação.

Quanto às organizações proponentes das 21 TS, 14 são organizações da sociedade civil, conforme gráfico 2. A maioria destas se apresenta constituída na forma de associação, mas há certa variação organizacional, sendo identificadas desde associações locais de trabalhadores (como a Associação dos Trabalhadores Agroextrativistas do Rio Acuti-Pereira e a Associação dos Trabalhadores Agroextrativistas da llha das Cinzas) até braços organizacionais de responsabilidade social de grandes empresas que atuam na região (como a Fundação Vale e a Fundação Orsa). Esta diversidade organizacional mostra que a temática de TS no estado perpassa diferentes lógicas de desenvolvimento, sejam estas reformistas, sejam de busca de ruptura ao modelo tecnológico convencional do sistema capitalista, conforme discutido na seção 2 . Se consideramos as diferenciações conceituais de França Filho (2003) e França Filho, Rigo e Souza (2020), quanto às organizações associadas a atuação de responsabilidade social de empresas, cabe observar que as TS implementadas não estão articuladas à ideia de economia solidária (ES) e sim vinculadas a outros repertórios de geração de renda, como os de atuação do terceiro setor, responsabilidade social corporativa e negócios sociais. 
Outros proponentes de TS de renda encontrados foram 5 organizações público-estatais, sendo 3 da esfera federal (todas instituições de ciência e tecnologia - ICT), 1 estadual e 1 municipal. Neste recorte, verificamos certa predominância de ICT, enquanto perfil institucional mais atuante em processos de desenvolvimento tecnológico, em geral, nas sociedades, mas ainda assim em quantidade tímida frente ao total de ICT federais situadas no estado (contabilizamos, ao menos, 7 no total - EMBRAPA, IFPA, MPEG, UFPA, UFRA, UFOPA, UNIFESSPA), além de outras estaduais e privadas. Desta forma, entendemos que a temática de tecnologia social ainda é emergente e com aplicações localizadas nas ICT do estado, demandando maior esforço de disseminação para o conjunto de organizações.

Para finalizar os perfis dos proponentes, realçamos que somente uma TS de renda teve como proponente uma cooperativa (Cooperativa Mista da Flona Tapajós - COOMFLONA), enquanto esperávamos identificar mais cooperativas como proponentes no estado. Ainda que consideremos todos os temas de TS implementadas no Pará (77), foram somente 2 cooperativas localizadas, a COOMFLONA e a CAMTA (Cooperativa Agrícola Mista de Tomé-Açu). Segundo a unidade do Pará da Organização das Cooperativas Brasileiras (OCB/PA), em 2020, houve 1.849 atendimentos a cooperativas (Sistema OCB/PA, 2020), não sendo, portanto, um universo inexpressivo no estado. Entendemos que o perfil organizacional baseado no cooperativismo é potencial ao desenvolvimento tecnológico alternativo a partir da concepção de TS, de acordo com o grau em que princípios de participação e cooperação são exercidos. Assim, no âmbito exploratório desta pesquisa, isso levanta a necessidade de aprofundamento futuro para compreender possíveis barreiras para inclusão da concepção de TS nas operações e formas de atuação de cooperativas do estado, bem como em organizações de apoio a estas.

Dentre as proponentes de TS no tema principal de renda, a maioria certificou somente uma TS no tema ao longo dos anos examinados, somente a Empresa Brasileira de Pesquisa Agropecuária (EMBRAPA) e o Polo de Proteção da Biodiversidade e Uso Sustentável dos Recursos Naturais (POLOPROBIO) certificaram duas TS implementadas no Pará. Além disso, $14(66 \%)$ organizações proponentes são sediadas no próprio estado do Pará e 6 (33\%) têm sede em outros estados (PE, PR, RJ, RS e SP), o que chama a atenção a ausência de organizações dos outros estados da Amazônia, podendo levantar a possibilidade de baixa interação intrarregional, com a presença maior de organizações das regiões Sul e Sudeste atuando no estado.

Gráfico 2: Organizações proponentes de TS com tema Renda certificadas pela FBB como implementadas no estado do Pará, no período de 2003 a 2019, por tipo de organização e local da sede.

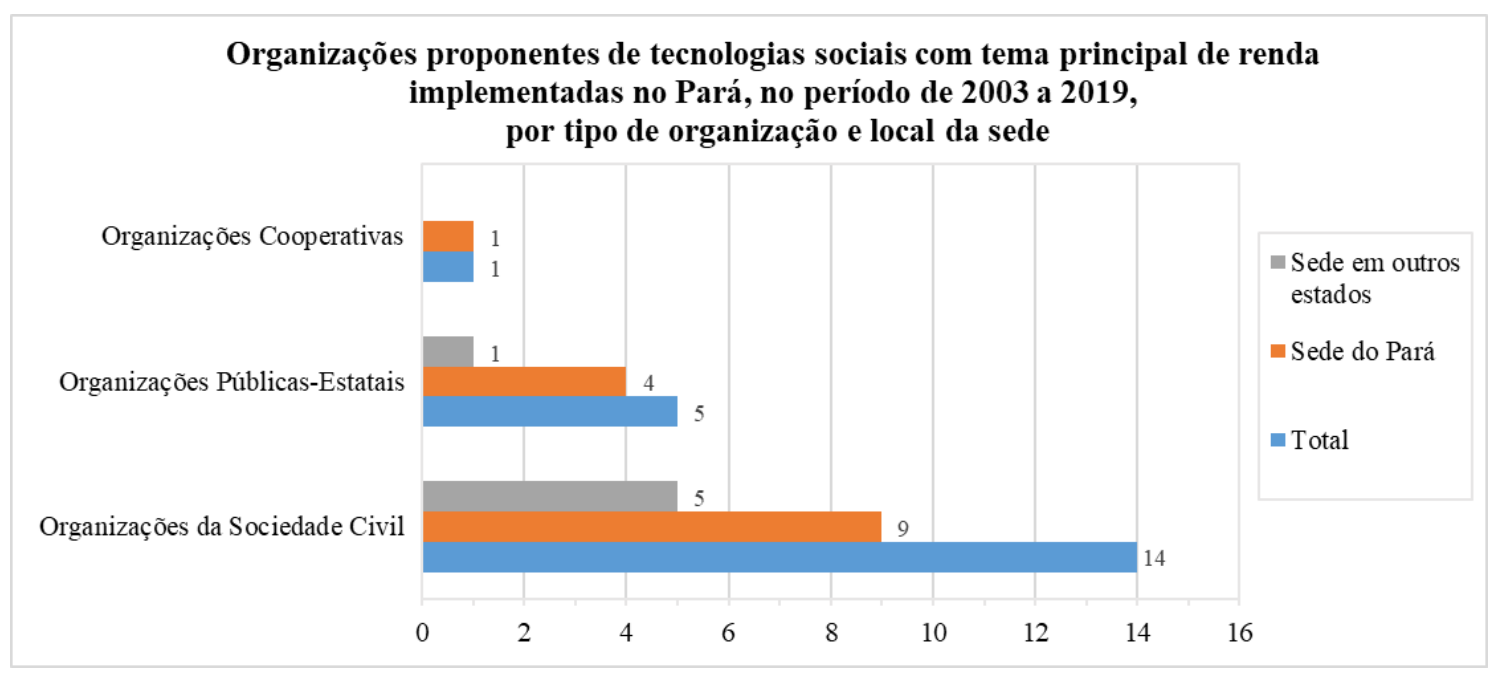


Fonte: Elaborado pelas autoras.

Por fim, buscamos identificar o perfil de público ao qual às TS estavam direcionadas, considerando a localização das áreas predominantemente aplicadas (rurais ou urbanas) e os segmentos de atuação principais. A maioria (14) das TS atendiam às áreas rurais, sendo 13 TS relacionadas a atividades de extrativismo e/ou agricultura (principalmente familiar) e $1 \mathrm{TS}$, cuja centralidade não estava em segmentos específicos de atuação, mas no fomento específico ao público feminino. Na predominância do ambiente urbano, identificamos 5 TS em segmentos de atuação diversos, como reciclagem de resíduos sólidos, produção cultural, qualificação profissional, agricultura urbana de plantas medicinais e banco comunitário. E, finalmente, 2 TS de escopo geral, relacionadas a programas de abrangência nacional, um programa de uma Fundação associada a uma empresa mineradora multinacional e outro programa associado a uma rede de economia solidária. Assim, de forma geral, observamos um potencial de aplicação de TS a diversos segmentos, sendo que a maioria das TS de geração de renda implementadas no Pará tem sua atenção dedicada para as áreas rurais e para as atividades de extrativismo de produtos nativos da região e da agricultura familiar.

A partir desse panorama geral, selecionamos uma TS para realizar um estudo de caso com o objetivo de compreender sua proposta de transformação social pela geração de trabalho e renda a partir dos quadros analítico-conceituais anteriormente discutidos.

\subsection{Estudo de Caso: tecnologia social dos Encauchados de Vegetais da Amazônia}

O caso selecionado foi a tecnologia social dos Encauchados de Vegetais da Amazônia implementada pela organização proponente POLOPROBIO, uma associação privada sem fins lucrativos. A tecnologia desta associação corresponde à produção coletiva de borracha natural em seringais por comunidades indígenas, quilombolas, assentados da reforma agrária e ribeirinhos. Ela é aplicável a diferentes produtos artesanais (bolsas, revestimentos de tecidos, utensílios domésticos e decoração, entre outros). Esta tecnologia social foi desenvolvida pela combinação de conhecimento popular destes povos e o conhecimento técnicocientífico (processo de vulcanização que proporciona qualidade e durabilidade à borracha) (POLOPROBIO, 2020). De acordo com o Diretor do Poloprobio:

Os Encauchados de Vegetais é uma nova maneira de produzir borracha com o viés de Tecnologia Social, Economia Solidária e Mercado Justo. Nele, a comunidade se apropria do conhecimento para ter qualidade de vida, bem-estar-social e manter a floresta em pé, que é o conceito da identidade dos seringueiros, melhor dizendo, não destruir as florestas dos territórios a qual eles ocupam (Entrevistado, 2020).

Conforme entrevista, o diretor do Poloprobio relatou que a origem do desenvolvimento da tecnologia social dos Encauchados de Vegetais surgiu a partir do início da década de 1990, quando durante o governo Collor, políticas públicas setoriais que existiam em prol de atividades extrativistas da borracha foram encerradas em meio o enxugamento do Estado promovido sob a ótica neoliberal. A forte desvalorização do mercado da borracha na Amazônia e o corte de subsídios deixou os seringueiros sem assistência governamental, incluindo tanto um processo de desregulamentação da produção e comercialização da borracha (com a 
perda de linhas de créditos junto aos bancos oficiais), quanto a própria desmobilização de professores rurais, médicos e dentistas que prestavam assistência às comunidades por programas públicos. Assim, se iniciou um processo de busca de novos usos, beneficiamentos e aplicações da borracha amazônica.

O desenvolvimento de aplicações alternativas pelos atuais dirigentes da associação começou na década de 1990, no Acre, com a ideia do "couro ecológico", por meio da aplicação do látex pré-vulcanizado ao tecido de algodão, a qual ficava emborrachado. No início da década de 2000 , foram implementadas experiências para uso de fibras vegetais em substituição ao tecido de algodão industrializado e o processo de vulcanização não industrial do látex, pela adição de um composto desenvolvido pela associação (POLOPROBIO, 2020). Do ponto de vista da mudança técnica, o ponto de partida para a TS foi o desenvolvimento de um processo artesanal e simplificado da vulcanização da borracha para conceder ao látex maior durabilidade. $\mathrm{O}$ objetivo era gerar uma solução para que as comunidades não priorizassem somente a extração da matéria-prima (látex), mas utilizassem a matéria-prima para o desenvolvimento de produtos, seja para uso próprio, seja para a comercialização.

Eu não poderia entrar nesse viés de Tecnologia Social e convencer o seringueiro a construir um processo produtivo diferente se não soubesse que esse produto teria qualidade. Então o nosso primeiro trabalho foi aperfeiçoar a questão tecnológica do processo produtivo e através disso nós tivemos que desconstruir o processo industrial de vulcanização para transformar ele em artesanal e dá acesso pelas comunidades. (Entrevistado, 2020).

A associação disseminou a TS via processos de capacitação do uso do látex vulcanizado artesanalmente em comunidades na Amazônia, iniciando por grupos de seringueiros e indígenas no Acre e Amazonas e, posteriormente, atuando também com outros grupos sociais como quilombolas e ribeirinhos no Pará. A associação contabiliza 75 comunidades atendidas, sendo a maioria das pessoas capacitadas $(75 \%)$ são mulheres (POLOPROBRIO, 2020). As capacitações são fomentadas via financiamento público governamental e não-governamental (como, por exemplo, o prêmio da FBB) e, posteriormente, agregou a parceria com a Cooperativa dos Ecoextrativistas da Amazônia (COOPERECO). Essa diversidade de fontes de recursos articulada no decorrer da trajetória para atendimento às comunidades está de acordo com a noção de hibridização de lógicas econômicas da economia solidária.

Conforme relatos dos dirigentes, embora o processo em si da vulcanização artesanal seja o mesmo, cada comunidade estabeleceu uma forma uso e preferências de produtos para o látex, o que permitiu uma troca de conhecimento e ganho de amplitude de opções aplicações, que foram sendo incorporadas em processos seguintes de reaplicação. A troca de conhecimentos técnicos e saberes das comunidades foi realçada como fator relevante para o desenvolvimento da TS, foi exemplificado a contribuição de comunidades indígenas ao desenvolvimento e reaplicações da TS ao resgatar a técnica indígena de produção de encauchados (extração do látex para confeccionar mantas, bolsas, panelas etc.) e tornar a borracha mais resistente e durável.

No início nós não sabíamos como seria a reação deles (comunidades indígenas), então fomos orientados pelo Antropólogo da Universidade Federal do Acre e ele falou que tínhamos que ir com muita cautela. Durante alguns dias nós fomos para a floresta junto com 
eles, colhemos e preparamos o látex e começamos a trabalhar os tecidos emborrachados e na hora de aplicar o látex no tecido, eles falaram que iria ficar mais bonito se tivesse uma cor por cima, então perguntamos para eles como faziam as cores porque nós não conhecíamos nada, eles falaram que tinham todas as cores, tinham urucum, jenipapo, cascas de árvores que dão cores, folhas de árvores que dão cores. Eles fizeram um mutirão para colher esses recursos na floresta, nós começamos a misturar com o látex e fazer o experimento, isso deu vida para o nosso trabalho, eles começaram a fazer desenho em cima do tecido e depois eles perguntaram para que servia aqueles tecidos e se podiam cortar, depois de um tempo todos eles estavam usando colete, totalmente artesanal feito por eles mesmos. Nós aprendemos muito com eles e levamos essa ideia para os seringueiros só que adaptando de acordo com as realidades deles. (Entrevistado, 2020).

Assim, observamos como a TS foi desenvolvida na interação com diferentes comunidades, envolvendo um processo de aprendizado cruzado, onde comunidades aprendiam a usar o látex vulcanizado artesanalmente para diferentes aplicações, de acordo com suas necessidades e interesses, e a associação aperfeiçoava os usos possíveis do látex, tanto em termos do processo (como a incorporação de corantes naturais a partir dos recursos da floresta), quanto em termos de diversidade de aplicações (como coletes, bolsas, utensílios e biojoias). Bem como, fica evidenciado como a reaplicação proporciona uma permanente abertura ou flexibilidade do processo tecnológico para ao mesmo tempo assegurar a autonomia a cada comunidade desenvolver o uso da TS de acordo com os recursos disponíveis em seus territórios, conhecimentos e necessidades; e permitir um acúmulo de conhecimentos e diferentes possibilidades de aplicações da TS a cada experiência de reaplicação realizada.

Além da participação no processo de aprendizado e desenvolvimento da TS, cabe também à cada comunidade local a tomada de decisão sobre o uso que farão da TS. Segundo os dirigentes do POLOPROBIO, há comunidades que utilizam a TS eventualmente, para produção de utensílios para uso próprio ou para comercialização como artesanato somente em ocasiões específicas (como festividades locais). Entendemos que essa dinâmica caracteriza uma ênfase da finalidade social sobre a preocupação com a viabilidade econômica, em que a TS ajuda na organização de iniciativas comunitárias que, embora envolvam lógicas econômicas (ganhos mercantis ou redução de custos domésticos), estas estão condicionadas à manutenção dos laços sociais e atividades coletivas. Por outro lado, há outras comunidades em que o uso da TS apresenta maior ênfase na geração de trabalho e renda, muitas vezes envolvendo mulheres que não tinham oportunidades de trabalho com ganhos monetários nas suas comunidades. Neste caso, a viabilidade econômica torna-se uma preocupação mais relevante, inclusive enquanto meio para alcançar a finalidade social de inclusão socioprodutiva.

Entendemos que as duas lógicas (de ênfase à finalidade social ou econômica) de uso da TS em comunidades da Amazônia acima relatadas fazem parte do universo da geração de trabalho e renda da ES, como discutido por França Filho, Rigo e Souza (2020). Contudo, a segunda configuração de uso, por um lado, mostra-se com maior potencial de inclusão socioprodutiva e, portanto, de transformação social, posto que geralmente mobiliza grupos na comunidade até então excluídos de oportunidades de trabalho e renda. Por outro lado, é nesta configuração em que a finalidade social e a gestão democrática ficam mais tensionadas pelas lógicas mercantis e tradicionais.

Compreendemos que esta TS proporciona várias potencialidades para geração de trabalho e renda via ES, como as principais: (1) valorização dos recursos da floresta e de sua biodiversidade, (2) ampliação das 
oportunidades de geração de renda a partir do látex da seringueira e (3) inclusão socioprodutiva das mulheres das comunidades.

Sobre a valorização dos recursos da floresta, além do látex coletado de seringueiras, existe uma diversidade de aplicações, com o uso sustentável de outros recursos como: corantes naturais (folhas, cascas de árvores e frutos), fibras vegetais e sementes. Esse conjunto integrado de recursos proporciona condições para atividades socioeconômicas que requerem a manutenção da floresta em pé e conservação da sua biodiversidade.

Ademais, a atividade de extração do látex e da borracha das seringueiras nativas da região tem sofrido desvalorização na comercialização in natura, levando a uma forte redução de renda das famílias em seringais e até mesmo o abandono da atividade, principalmente por jovens. Desta maneira, as alternativas de uso e beneficiamento, na própria comunidade, cria uma demanda interna que valoriza a atividade e pode complementar a renda das famílias. Essa valorização tem permitido a reativação e manejo de seringais nas comunidades onde a TS foi implementada.

Por fim, a extração do látex e da borracha foi historicamente associada ao trabalho masculino, em diferentes comunidades tradicionais extrativistas da região (desde as próprias comunidades seringueiras até ribeirinhas e quilombolas). Enquanto isso, as mulheres das comunidades eram responsáveis pelas tarefas domésticas não-remuneradas (tradicionalmente menos valorizadas socialmente) e dependentes economicamente dos homens. A TS, ao aliar o látex ao artesanato, atividade tradicionalmente associada às mulheres, oferece uma oportunidade de trabalho e fonte de renda para estas, empoderando-as e promovendo a igualdade de gênero.

Contudo, como citamos, o potencial de produção com fins comerciais do artesanato baseado na TS tensiona desafios. Realçamos três conjuntos de desafios: (1) os desafios organizacionais para comercialização do artesanato fora das comunidades locais produtoras; (2) a desigualdade de gênero e o equilíbrio de incentivos entre homens e mulheres; (3) ausências de políticas públicas intersetoriais e de longo prazo.

O primeiro conjunto de desafios envolve diversas dificuldades organizacionais para comercialização justa dos produtos artesanais fora das comunidades de origem. Como relatado anteriormente, cada comunidade após capacitada no uso da TS pode decidir pela comercialização ou não dos produtos com base na tecnologia. Contudo, caso se tenha interesse de comercializar há dificuldades devido a maior parte dessas comunidades ficar fora dos perímetros urbanos, com difíceis condições de infraestrutura e com baixo nível de circulação monetária. Assim, a comercialização dos produtos fora delas representa a fonte substancial para ampliação de renda das famílias, no entanto a lógica de produção familiar (o artesanato é geralmente realizado em conjunto a outras atividades domésticas) e a escala de produção (a produção das famílias é geralmente pequena e descentralizada) são tensionadas pela lógica mercantil quanto aos custos e canais de comercialização.

A própria Associação (POLOPROBIO) identificou dificuldades quando buscou a comercialização de sua produção própria de artesanato baseado nos Encauchados de Vegetais e ao perceber a falta de outros mecanismos de apoio organizacional junto as comunidades onde a TS havia sido reaplicada, por exemplo, a aplicação de metodologias de incubadoras de empreendimentos populares e incentivos de estruturação de comércio justo. Para enfrentar esta dificuldade o POLOPROBIO estruturou e começou a oferecer um canal para comercialização. A associação realizou parcerias com a COOPERECO e lojas nacionais identificadas com a concepção de comércio justo. A associação ainda criou uma identidade para a comercialização de produtos baseados na TS, chamada de "Seringô". Caso as comunidades queiram, a Associação articula o recebimento das produções e direciona para as lojas parceiras, repassando às comunidades o valor de compra dessas lojas. De forma análoga, quando há alguma demanda específica das lojas parceiras, a Associação aciona as comunidades. Atualmente, os produtos baseados em Encauchados de Vegetais estão presentes em 20 pontos de vendas em Belém, Recife, Belo Horizonte, 
Florianópolis, São Paulo e Rio de Janeiro. Conforme cálculos da Associação, o artesanato pode gerar renda de cerca de 01 a 02 salários-mínimos por família (PROGRAMA DE ACELERAÇÃO PPA, 2020).

Apesar da Associação oferecer por livre adesão o canal de comercialização às comunidades, cabe observar algumas dificuldades do ponto de vista da Associação e das comunidades devido à lógica mercantil. Parte do desenvolvimento da estruturação do canal de comercialização foi idealizado pela participação da Associação no Programa de Aceleração da PPA (Plataforma Parceiros pela Amazônia). O programa prevê a aceleração de negócios de impacto social na região, portanto busca aliar operação ambientalmente sustentável, criação de impacto social e sustentabilidade financeira do negócio. Para tanto, o programa oferece fomento e mentoria de parceiros do setor privado aos negócios, bem como assessoria de design e comunicação, entre outras. Assim, a viabilidade financeira do empreendimento torna-se um indicador relevante, subordinando o empreendimento à lógica do mercado, o que tensiona a possibilidade de conciliação com a finalidade social na perspectiva da ES.

Para estabelecer as parcerias com lojas e prover viabilidade financeira ao empreendimento de comercialização do artesanato, a Associação enfrentou o desafio de manter linhas de produtos com alguma estabilidade de produção para atender a demanda e acompanhar os custos logísticos e de comercialização. Em geral, o artesanato não é a atividade econômica principal das comunidades e tais atividades principais muitas vezes envolvem períodos de safra ou intensificação de produção de acordo o recurso (por exemplo, açaí), quando a produção de artesanato pode ser totalmente interrompida, assim a flutuação desta produção de artesanato nas comunidades é elevada. Para permitir a livre tomada de decisão quanto à adesão e à produção das comunidades, mas evitar o desabastecimento, a Associação mantém uma produção própria de artesanato para o negócio social. Entendemos que essa solução viabiliza o negócio ao mesmo tempo em que proporciona liberdade às comunidades para a tomada de decisão quanto à produção. Contudo, a solução encontrada tenciona a noção de autogestão, visto que cria internamente ao negócio uma lógica de produção mercantil insulada, com ênfase na viabilidade econômica. Assim, estrutura-se um canal de comercialização do qual as comunidades podem usufruir para gerar renda, no entanto não há viabilidade de maior incidência e participação destas na gestão do canal de comercialização, dada às exigências de estruturação da operação para o mercado.

Outro conjunto de desafios corresponde a identificação por parte dos executores do POLOPROBIO de dinâmicas de desigualdade de gênero nas comunidades e a busca de estratégias para equilibrar incentivos entre homens e mulheres. Como relatado, historicamente a extração do látex e da borracha em comunidades ribeirinhas ou seringueiras era uma atividade masculina de geração de renda, sendo esta principal ou complementar. A extração da borracha, atividade que gerava mais renda, demanda visitas mais espaçadas aos pontos de coleta nos seringais, enquanto o látex para a TS exige a extração frequente para o processo de vulcanização. Foi observado pelos executores do POLOPROBIO durante o período de capacitações em comunidades ribeirinhas (onde a extração da borracha/látex não é a atividade econômica principal) resistências de uma parte dos homens em extrair frequentemente o látex para o artesanato, o qual era majoritariamente exercido pelas mulheres.

Nesse cenário, a COOPERECO desenvolvia outro projeto que visava à aplicação da borracha pura natural para produção de sandálias e calçados. Contudo, para um processo sem aditivos químicos industriais, a produção de calçados requeria uma metodologia de extração de borracha "limpa", sem os resíduos da floresta (folhas, caroços, cascas etc.) que geralmente se misturavam ao látex durante os dias de extração e composição. Como a extração da borracha para comercialização direta era mais valorizada por parte dos homens das comunidades do que a extração do látex para o artesanato, o POLOPROBIO começou a reaplicar a TS de Encauchados de Vegetais em algumas comunidades ribeirinhas no Pará associada a outra capacitação, correspondente a metodologia de extração de borracha "limpa", a qual a COOPERECO poderia adquirir. Assim, eram realizadas oficinas da TS de Encauchados em que tendiam a participar 
majoritariamente as mulheres, em associação com capacitações de extração de borracha limpa, que tendiam a obter maior adesão entre os homens da comunidade.

Segundo informações do POLOPROBIO, em valores de 2020, o quilo da borracha era vendido pelos seringueiros diretamente às usinas e indústrias por $R \$ 2,00$, enquanto o acordo obtido com a cooperativa incluía a antecipação desse valor base $(2,00)$ aos cooperados, mais um acréscimo estimado em $R \$ 5,00$ pelo resultado da operação da cooperativa na comercialização dos calçados.

O desenho de capacitação conjunta realizadas nessas comunidades do Pará foi percebido como eficaz pelo POLOPROBIO ao criar incentivos de geração de renda adicional tanto na venda direta da borracha, quanto na realização do artesanato baseado na TS. Além disso, a extração da borracha "limpa" exigia a presença mais frequente do seringueiro nos locais de extração para realizar a limpeza dos repositórios, o que conciliava também com a extração do látex mais frequente para a realização do artesanato. Assim, há uma ampliação de oportunidades de geração de renda que atende tanto às atividades tradicionais de homens e mulheres dessas comunidades, equilibrando os incentivos.

Embora entendamos que esse desenho não resolva as dinâmicas de desigualdades de gênero estabelecidas nas comunidades, ele favorece a viabilidade da geração de renda pelas mulheres por meio do artesanato. Essa geração de trabalho contribui para a inclusão socioprodutiva destas e permite o empoderamento não somente pela renda gerada, mas por processos de aprendizagem e participação em tomada de decisões que podem conduzir a outras transformações sociais futuras. Compreendemos que o enfrentamento de processos de desigualdades constitui um ponto fundamental para a transformação social, no entanto este requer geralmente maior prazo e a articulação de mudanças em diferentes dimensões sociais, políticas e econômicas. Neste contexto mais amplo que emerge o terceiro conjunto de desafios que identificamos relacionado a ausência de políticas públicas intersetoriais e de longo prazo envolvendo o fomento à tecnologia social e à economia solidária.

A partir dos resultados discutidos nesta seção, identificamos uma amostra de experiências de TS de geração de trabalho e renda na Amazônia, mais especificamente no estado do Pará, que abrange uma diversidade de possíveis aplicações de TS tanto em âmbito rural, quanto urbano, para múltiplos segmentos socioeconômicos. Nesta diversidade, encontramos uma ênfase às atividades extrativistas e de agricultura familiar, o que entendemos refletir uma demanda de geração de trabalho e renda para populações em área rurais e com necessidade de conciliar a atividade socioeconômica com a conservação ambiental. Embora esses resultados realcem um potencial de uso de TS na região para geração de trabalho e renda com sustentabilidade, também observamos que as experiências catalogadas na base analisada (FBB) estão restritas a poucos municípios.

O caso específico em análise da TS de Encauchados de Vegetais nos permitiu compreender em maior profundidade possíveis estratégias, potencialidades e desafios de implementação e reaplicação de TS. Dentre as principais potencialidades identificamos a valorização dos recursos da floresta aliada a preocupação de conservação ambiental, a ampliação das oportunidades de geração de trabalho e renda em comunidades da região e a inclusão socioprodutiva, principalmente das mulheres. Contudo, também observamos desafios relacionados com o tensionamento dos princípios da economia solidária pela lógica de mercado no processo de comercialização de produtos, com as dinâmicas de desigualdades (principalmente de gênero) e com a ausência de políticas públicas de fomento à TS, principalmente aquelas de atuação intersetorial e de longo prazo que proporcionassem incentivos mais estruturados para desenvolvimento e reaplicações dessas experiências.

\section{Considerações finais}


Diante dos resultados desta pesquisa, entendemos que o desenvolvimento ou reaplicação tecnológica a partir das TS apresenta potencial de uso para geração de trabalho e renda nos diferentes territórios da região Amazônica. Esse potencial se mostra responsivo a uma diversidade de dinâmicas socioeconômicas em territórios, desde aquelas baseadas no extrativismo florestal ou na agricultura familiar, até aquelas de base urbana. Interpretamos que este potencial está relacionado à concepção da construção sociotécnica, a qual incorpora e valoriza os saberes e interesses dos usuários no desenvolvimento tecnológico, bem como busca garantir que eles se apropriem do conhecimento e da tecnologia gerados. Portanto, essa concepção de desenvolvimento (e reaplicação) tecnológico se torna apta a estabelecer diálogos entre tradições socioculturais de diferentes povos (indígenas, quilombolas, ribeirinhos, provenientes de programas de assentamento rurais, entre outros) que se encontram na região e que, em muitas situações, demandam soluções de geração de trabalho e renda.

Assim, a incorporação da noção de TS como concepção orientadora de desenvolvimento tecnológico em ações e políticas públicas de geração de trabalho e renda mostra é potencialmente favorável às formas de implementação que tenham como princípios norteadores a geração de transformação social, a governança democrática e a autogestão, também associados à lógica do campo de Gestão Social. Contudo, consideramos que tal concepção tende a enfrentar, além dos desafios ressaltados na seção anterior, um desafio de disseminação de conhecimento entre os atores públicos na região quanto a concepção de TS, o que inclui diversas organizações, como os órgãos governamentais, responsáveis por políticas e programas voltados a estes grupos sociais; as ICT; e outras entidades de apoio privadas ou híbridas, como àquelas de apoio à cooperativas e pequenos empreendimentos.

Perante este desafio, refletimos quanto a duas direções de pesquisas futuras interrelacionadas: (1) aprofundamento de estudos sobre os processos de disseminação tecnológica alternativa e de aprendizagem social como esteios para a reaplicação (adequação sociotécnica) de TS; e (2) estudos sobre como a concepção de TS (construção/adequação sociotécnica) pode ser incorporada no processo de ações e políticas públicas, de modo a constituir ações e políticas públicas de geração endógena nos diferentes territórios da região Amazônica, que considerem os saberes e valores dos atores locais, bem como tenham como princípio a conservação da sociobiodiversidade.

\section{Referências}

ARAÚJO, R. O. A.; CANDIDO, G. A. Tecnologia social e inovação social: Interação Indutora do Desenvolvimento Sustentável nos Territórios Rurais. Revista Espacios, v. 36, n. 13, p. 05-06, 2015.

BARROS, Márcio Júnior Benassuly et al. Fronteira agrícola e conflitos territoriais nas Amazônias Brasileiras: a expansão do agronegócio da soja e seus efeitos no planalto de Santarém, Pará-Amazônia-Brasil. Ciência Geográfica, 2020.

BIJKER, Wiebe E. Of bicycles, bakelites, and bulbs. Cambridge: MIT Press, 1995.

CANÇADO, Airton Cardoso. Para a Apreensão de um Conceito de Cooperativa Popular, 2004. Enanpad, n. 16, p. 02.

CANÇADO, Airton Cardoso; PEREIRA, José Roberto; JÚNIOR, Jeová Torres Silva. Economia solidária, cooperativismo popular e autogestão: as experiências em Palmas-TO. UFT-Universidade Federal do Tocantins, NESol-Núcleo de Economia Solidária, 2007. 
DAGNINO, Renato P. Neutralidade da Ciência e Determinismo Tecnológico: Um debate sobre a tecnociência. Campinas, SP: Editora da Unicamp, 2008.

DAGNINO, R; BRANDÃO, F.C; NOVAES, H.T. Sobre o Marco Analítico-Conceitual da Tecnologia Social. Campinas. 2010.

DALLABRIDA, Valdir Roque. A gestão social dos territórios nos processos de desenvolvimento territorial: uma aproximação conceitual. Sociedade, Contabilidade e Gestão, v. 2, n. 2, 2010.

ESPADA, Ana Luiza Violato; SOBRINHO, Mário Vasconcellos. Manejo comunitário e governança ambiental para o desenvolvimento local: análise de uma experiência de uso sustentável de floresta na Amazônia. Administração Pública e Gestão Social, v. 7, n. 4, p. 169-177, 2015.

FBB - FUNDAÇÃO BANCO DO BRASIL. Transforma, 2020. Rede de Tecnologias Sociais. Disponível em: https://transforma.fbb.org.br/. Acesso em: 14 de set. 2020.

FBB - FUNDAÇÃO BANCO DO BRASIL. Tecnologia Social: Uma Estratégia Para o Desenvolvimento: Rio de Janeiro, 2004.

FRANÇA FILHO, Genauto Carvalho de. Terceiro setor, economia social, economia solidária e economia popular: traçando fronteiras conceituais. Bahia Análise e Dados, v. 12, n. 1, 2002.

FRANÇA FILHO, Genaulto C. A Temática da Economia Solidária e suas Implicações Originais para o Campo dos Estudos Organizacionais: Rio Janeiro, 2003.

FRANÇA, Genauto Carvalho de; RIGO, Ariádne Scalfoni; SOUZA, Washington José de. A reconciliação entre o econômico e o social na noção de empresa social: limites e possibilidades (no contexto brasileiro). Organizações \& Sociedade, v. 27, p. 556-584, 2020.

INSTITUTO DE TECNOLOGIA SOCIAL - ITS. Uma Metodologia das Análise de Tecnologia Social: Brasil, 2007.

INSTITUTO DE TECNOLOGIA SOCIAL - ITS. Caminhos e Perspectivas para a Tecnologia Social. Brasília: ITS Brasil. 2018, 68 p.

NARDI. H.C; YATES, D.B; FERNANDES, J.M; RODRIGUES, M.C. Subjetividade e Solidariedade: A Diversidade das Formas de Implicação dos Jovens na Economia Solidária. Revista Psicologia: Reflexão e Crítica. v. 19, n. 02, p. 320, 2006.

POLANYI, K. A grande transformação: As origens das políticas econômicas de nossa época (2a ed.). Rio de Janeiro, RJ: Elsevier, 2000.

POLOPROBIO - Polo de Proteção da Biodiversidade e Uso Sustentável dos Recursos Naturais, Encauchados de Vegetais na Amazônia. Disponível em: http://www.poloprobio.org.br/. Acesso: 16 de set. 2020

Programa de Aceleração PPA. Novos Modelos de Desenvolvimento para a Amazônia, 2020. Disponível em: http://aceleracao.ppa.org.br/portfolio-de-negocios/encauchados/. Acesso: 29 de set. 2020.

RADOMSKY, Guilherme Francisco Waterloo. Desenvolvimento, pós-estruturalismo e pós-desenvolvimento: a crítica da modernidade e a emergência de" modernidades" alternativas. Revista Brasileira de Ciências Sociais, v. 26, p. 149-162, 2011.

RTS, Rede de Tecnologia Social. Tecnologia Social e Desenvolvimento Sustentável: Contribuições da RTS para a formulação de uma Política de Estado de Ciência, Tecnologia e Inovação. Brasília/DF: Secretaria Executiva da Rede de Tecnologia Social (RTS), 2010. 98 p.

SACHS, Ignacy. Desenvolvimento: includente, sustentável, sustentado. Rio de Janeiro: Garamond, 2008. 
SINGER, Paul. Economia solidária. Estudos avançados, v. 22, n. 62, p. 289-314, 2008.

THEIS, Ivo Marcos; STRELOW, Daniel Rodrigo; LASTA, Tatiane Thaís. CT\&I e desenvolvimento desigual no Brasil: é possível outro "modelo de desenvolvimento"?. Revista Tecnologia e Sociedade, v. 13, n. 27, p. 43-61, 2017.

THOMAS, Hernán; JUÁREZ, P.; PICABEA, F. ¿Qué son las tecnologías para la inclusión social? Colección Tecnología y Desarrollo. Bernal: Editorial UNQ, 2015.

VASEN, Federico. Is there a"post-competitive turn" in science and technology policy?. Sociologias, v. 18, n. 41, p. 242-268, 2016.

YIN, R.K. Estudo de Caso: Planejamentos e Métodos: Porto Alegre, 2001. 